Review Article

\title{
Cytokine-, Neurotrophin-, and Motor Rehabilitation-Induced Plasticity in Parkinson's Disease
}

\author{
Gabriella Policastro, ${ }^{1}$ Matteo Brunelli, ${ }^{1}$ Michele Tinazzi, ${ }^{2}$ Cristiano Chiamulera, ${ }^{1}$ \\ Dwaine F. Emerich, ${ }^{3}$ and Giovanna Paolone $\left.{ }^{1}\right)^{1}$ \\ ${ }^{1}$ Department of Diagnostic and Public Health, University of Verona, Verona, Italy \\ ${ }^{2}$ Department of Neuroscience, Biomedicine and Movement, University of Verona, Verona, Italy \\ ${ }^{3}$ Glocester, Rhode Island, USA \\ Correspondence should be addressed to Giovanna Paolone; giovanna.paolone@univr.it
}

Received 11 September 2020; Revised 6 November 2020; Accepted 19 November 2020; Published 26 November 2020

Academic Editor: Andrea Turolla

Copyright (c) 2020 Gabriella Policastro et al. This is an open access article distributed under the Creative Commons Attribution License, which permits unrestricted use, distribution, and reproduction in any medium, provided the original work is properly cited.

\begin{abstract}
Neuroinflammation and cytokine-dependent neurotoxicity appear to be major contributors to the neuropathology in Parkinson's disease (PD). While pharmacological advancements have been a mainstay in the treatment of PD for decades, it is becoming increasingly clear that nonpharmacological approaches including traditional and nontraditional forms of exercise and physical rehabilitation can be critical adjunctive or even primary treatment avenues. Here, we provide an overview of preclinical and clinical research detailing the biological role of proinflammatory molecules in PD and how motor rehabilitation can be used to therapeutically modulate neuroinflammation, restore neural plasticity, and improve motor function in PD.
\end{abstract}

\section{Introduction}

$\mathrm{PD}$ is the second most common neurodegenerative disorder generally affecting the population over 65 . In fact, only $4 \%$ of cases occur before the age of 50 [1]. The disease is induced by the loss of nigrostriatal dopaminergic neurons, intracellular $\alpha$-synuclein accumulation, and onset of motor symptoms such as abnormal voluntary movements, tremor, rigidity, slowness of movement, postural instability [2], and nonmotor impairments including cognitive decline [3], depression, and sleep disturbances [4].

However, recently, postmortem brain imaging and fluid biomarker investigations identified neuroinflammation as a crucial pathogenesis factor of PD [5-7]. Neuroinflammation is marked by activated microglia and reactive astrocytes within brain parenchyma and by the release of various inflammatory mediators including cytokines, chemokines, reactive oxygen species (ROS), and reactive nitrogen species (RNS) [8]. These mediators can be secreted by microglia in the central nervous system (CNS), peripheral immune cells, and other cell types such as dysfunctional adipocytes [9,
10], sustaining the inflammatory reaction and maintaining a self-reverberating cycle. For a long time, the blood-brain barrier (BBB) was thought to be unaffected by neurodegenerative and neurological pathologies while nowadays, a growing body of evidence suggests that the BBB is pathologically modulated, allowing the penetration of peripheral macrophages, leukocytes, and systemic proinflammatory mediators, such as monocyte chemotactic protein-1 (MCP-1), tumor necrosis factor- $\alpha$ (TNF- $\alpha$ ), interleukin-1 $\beta$ (IL-1 $\beta$ ), interleukin-8 (IL-8), and interferon- $\gamma$ (IFN- $\gamma$ ) [11-15]. The overproduction of proinflammatory mediators also reduces the production of brain plasticity-related molecules, such as brain-derived neurotrophic factor (BDNF) and glial cell line-derived neurotrophic factor (GDNF), and the ability of CNS to adapt in response to a variety of external stimuli $[16,17]$. In addition, in recent years, researchers have focused their attention on the beneficial effect of physical exercise on PD patients suggesting that exercise, through targeted training, can increase neuroplasticity and, in turn, improve patients' motor and cognitive performance [18]. Here, we intend to explore (1) the role of proinflammatory cytokines 
and (2) the impact of traditional and not traditional forms of physical exercise on neuroinflammation and neuroplasticity in parkinsonian subjects undergoing motor rehabilitation.

To reach the aim of this study, publication search for literature review was conducted using the NCBI PubMed database based on the following groups of keywords: (1) Parkinson's disease, pro-inflammatory cytokines; (2) Parkinson's disease, IL-6, IL- $1 \beta$, IL-8, MCP-1, and TNF- $\alpha$; (3) Parkinson's disease, neuroinflammation, neuroplasticity; (4) Parkinson's disease, physical activity, neurorestoration, neuroplasticity; (5) Parkinson's disease, exercise, neurotrophic factors; (6) Parkinson's disease, exercise, BDNF; (7) Parkinson's disease, exercise, GDNF; (8) Pro-inflammatory cytokines, exercise, PD patients; and (9) Not traditional physical exercises, inflammatory state, PD patients. To be eligible for inclusion in the review, studies must have been published between 1990 and 2020 .

\section{Proinflammatory Cytokines in PD}

Brain cytokine activity depends on several conditions such as the cellular sources and the pathophysiological context all contributing to the effects exerted on the brain. In fact, cytokines can promote apoptosis of neurons, oligodendrocytes, and astrocytes; cause damage to myelinated axons; but even initiate neuroprotective effects, independently of their immunoregulatory properties [19]. Although to date there is no evidence to support a specific role for any particular cytokine as a direct cause of neurodegenerative conditions, cytokinedriven neuroinflammation and neurotoxicity have been shown to modify the disease progression.

Among cytokines, interleukin-6 (IL-6), IL-1 $\beta$, IL-8, MCP-1, and TNF- $\alpha$ have been the most studied in PD.

2.1. $I L-1 \beta$. IL- $1 \beta$ is a proinflammatory cytokine produced mainly by macrophages and monocytes [20] and also by epithelial cells [21] and endothelial cells [22], and it has a key role in regulating inflammatory response to microbial stimuli such as the lipopolysaccharide (LPS) and sterile insults (e.g., hypoxia, hyperosmolarity, thermal damage, and gamma radiation) $[23,24]$.

It has been demonstrated that IL- $1 \beta$, a part of the IL-1 family, acts on the CNS because of the permeability of the $\mathrm{BBB}$ [25], and it is also secreted into the CNS by microglial cells [26-28], astrocytes [29], oligodendrocytes [30], and neurons $[31,32]$. Therefore, the presence of members of the IL- 1 family and in particular IL- $1 \beta$ and its receptor in basal conditions in the CNS could suggest a normal physiological role for IL-1 $\beta$. For instance, several studies demonstrate that IL-1 $\beta$ stimulates astrocytes and supports neuronal survival via production of neurotrophic factors $[33,34]$. However, IL-1 $\beta$ contributes to and/or sustains the pathological processes and results upregulated in several neurodegenerative diseases. Increased IL- $1 \beta$ levels have been detected in the cerebrospinal fluid (CSF) and the striatum of postmortem PD patients [35] as compared to control subjects. Moreover, studies based on adenoviral vectors reported that sustained expression of IL- $1 \beta$ in the substantia nigra $(\mathrm{SN})$ causes irreversible and pronounced dopaminergic neu- ronal loss and motor symptoms $[36,37]$, while IL- $1 \beta$ increase induced by acute administration of LPS in the SN was not toxic $[38,39]$. Overall, these data suggest that sustained but not acute IL- $1 \beta$ expression has toxic effects on the SN. In addition, loss of tyrosine hydroxylase- (TH-) positive neurons was higher in animals that received both, a stimulus of LPS in the SN and 6-OHDA injection into the striatum, compared to those receiving just an acute stimulus of LPS [39].

Nonetheless, Saura and colleagues have demonstrated that an acute infusion of a high dose $(20 \mathrm{ng})$ of IL- $1 \beta$ in the $\mathrm{SN}$ of rats 5 days before the injection of 6-hydroxy dopamine (6-OHDA) in the striatal region protects dopaminergic cellular bodies from 6-OHDA, does not induce microglia activation, and prevents motor dysfunctions [40]. Therefore, although most of the evidence reveals that an inflammatory stimulus previous to a neurodegenerative treatment increased neuronal cell death $[36,37,39]$, under specific circumstances, protective effects cannot be ruled out.

2.2. IL-6. IL-6 is a member of the neuropoietic cytokine family with a wide range of biological activities. It is involved in the development, differentiation, degeneration, and regeneration of neurons in the central and peripheral nervous systems and can also stimulate glial cells [41, 42]. Dysregulation of IL-6 production and signalling has also been reported in several neurodegenerative diseases, including PD [43-45]. Interestingly, IL-6-mediated neuronal degeneration in the CNS [46] and IL-6-mediated biological activities $[47,48]$ depend, respectively, on the activation of two different types of IL-6 pathways: the " transsignalling "and "classical signalling." Classical signalling occurs when the $80 \mathrm{kD}$ subunit of the IL-6 receptor, called IL-6r, binds to the protein. The binding of IL- 6 to IL-6r is followed by homodimerization of the second receptor subunit, called gp130, and by the activation of two distinct signalling pathways: (1) the Janus kinase- (JAK-) signal transducer and activator of transcription (STAT) pathway (JAK/STAT signalling pathway) and (2) the mitogen-activated protein kinase (MAPK)/extracellular signal-regulated kinase (ERK) signalling pathway [49-51]. While IL-6r is only expressed by hepatocytes, neutrophils, monocytes/macrophages, and specific lymphocyte subpopulations [52], IL-6 affects many more cell types. This is possible because of "transsignalling": IL-6r exists in a soluble form, sIL-6r, which can bind to IL-6 and develop a circulating IL-6/sIL-6r complex which can induce the dimerization of the gp130 even in cells that do not possess IL-6r. Activation of the IL- 6 pathway by IL6/sIL-6r is known as transsignalling $[53,54]$. The two pathways lead to two different cellular responses [55]. The classical pathway mediates anti-inflammatory signals while the transsignalling pathway mediates proinflammatory signals (e.g., IL-6 mediates neurodegeneration [46], cancer inflammatory response in the colon [56], and inflammatory bowel disease [57]). This emphasizes the importance of distinguishing between the two pathways when prescribing drugs for the treatment of neurological or neurodegenerative diseases [58].

In regard to the expression of IL- 6 in $\mathrm{PD}$, there are some controversial results. Several studies observed an increase of IL-6 in the nigrostriatal region of the postmortem brain 
and in CSF of PD patients [35, 43, 59, 60]. In some studies, no difference in plasmatic levels of IL-6 was reported [60, 61], while others found elevated levels in PD patients with severe depression [62]. Still, one paper reported that IL-6 was at higher plasmatic levels in patients with a rapidly progressing disease compared to patients with usual progression [62]. Interestingly, it has been shown that Levodopa, in physiological concentrations, elicits an immunomodulatory effect on cells from both PD patients and controls and caused stimulation of IL-6 production [44].

2.3. IL-8. IL-8 is a chemoattractant cytokine secreted by a variety of cells (e.g., monocytes [63], macrophages [64], endothelial cells [65], dermal fibroblasts [66], keratinocytes [67], hepatoma cells [68], synovial cells [69], and chondrocytes [70]), and it is well known as an inflammatory factor which induces a chemotactic response involving infiltration of neutrophils through the BBB [71]. Moreover, activated microglia is also a potent secretory source of IL-8 and expresses CXCR2 receptor for the chemokine providing a positive feedback mechanism for sustained amplification of inflammatory response [72]. At present, few studies have examined levels of IL-8 in the PD brain. In one study of Koziorowski and collaborators, serum levels of the chemokine were measured in individuals diagnosed with idiopathic PD and in controls. The results showed that IL- 8 concentrations were doubled in the diseased brain compared with the control; this difference in levels of the chemokine was significant [73]. However, a contrary finding has recently been reported. Levels of IL- 8 and cytokine TNF- $\alpha$ were found reduced in serum from Indian PD patients relative to controls [74]. Overall, despite the relevance of neuroinflammation in the pathophysiology of $\mathrm{PD}$, data is lacking on the roles of IL-8 and other chemotactic factors in the progression of the disease.

2.4. MCP-1 (CCL2). MCP-1 (CCL2), one of the most highly and transiently expressed chemokines during inflammation, is a member of the CC subtype chemokines. MCP-1 exerts its biological functions by binding to its high-affinity receptor, CCR2, which is mainly expressed by microglia, astrocytes, and brain microvascular endothelial cells (BMECs) in the brain $[75,76]$.

Several studies have demonstrated that MCP-1 is constitutively present in the brain. The neuronal expression of MCP-1 is mainly found in the cerebral cortex, globus pallidus, hippocampus, lateral hypothalamus, Purkinje cells, cerebellum, astrocytes, perivascular microglia, infiltrating leukocytes, cholinergic neurons of magnocellular preoptic, and in dopaminergic neurons of the substantia nigra pars compacta $[77,78]$. The low expression in discrete neuroanatomical regions with classical neurotransmitters or neuropeptides suggests that MCP-1 may act as a modulator of neuronal activity and neuroendocrine functions [79].

Additionally, MCP-1 may modulate the function of the $\mathrm{BBB}$ components and thus affect the integrity of BBB. In accordance with this hypothesis, the MCP-1 level has been found to positively correlate with the permeability of the $\mathrm{BBB}$ and progression of diseases $[80,81]$ while the lack of
MCP-1 or CCR2 prevents neuronal death, decreases BBB permeability, and improves neuronal function in some disorders, including hemorrhage and ischemia-reperfusion injury $[81,82]$.

It has also been established that MCP-1 is an important mediator in several neuroinflammatory and neurodegenerative brain diseases characterized by neuronal degeneration such as PD.

MCP-1 levels in the blood are heightened in PD subjects compared to controls and correlate with $\mathrm{PD}$ progression [83].

Furthermore, it has been shown that MCP-1 could be implicated not only in disease progression but also in pathogenesis. The Ccl2-2518A allele is associated with lower MCP1 production and reduced transcriptional activity following IL-1 $\beta$ stimulation [84], and in genetic epidemiological studies, possession of this allele is associated with a delayed onset of PD compared with patients expressing the Ccl2-2518G allele [85].

2.5. TNF- $\alpha$. TNF- $\alpha$ is a proinflammatory cytokine well known for its role in chronic peripheral and central inflammation. TNF- $\alpha$ functions are mediated by two receptors: TNF-R1 (TNF-RSF1a) and TNF-R2 (TNFRSF1b). TNF-R1 is expressed in most tissues while TNF-R2 is found in limited cell types including cells of the immune system, oligodendrocytes, and certain neuron subtypes [10]. Both types of receptors are also expressed in the cortex, the subventricular zone of the lateral ventricle, and the hippocampus [86]. In homeostatic conditions, the TNF- $\alpha$ gene expression is low but increases dramatically in stressing conditions such as infection, trauma, and pathologies. In the CNS, TNF- $\alpha$ regulates a wide range of cellular processes and exhibits pleiotropic effects with positive or negative outcomes on the brain depending on concentrations and physiological or pathological state $[87,88]$. Among the positive effects of TNF- $\alpha$, there are increased neurogenesis and synaptic transmission [10, 89]. It has also been shown to be protective of hippocampal neurons by suppressing the accumulation of ROS and maintaining intracellular calcium levels [90]. Moreover, it modulates glutamatergic transmission, supports neural progenitor cell survival by mediating antiapoptotic signals via TNF-R2, and has a role in cognitive impairment, confirmed by investigations in TNF- $\alpha$ knock-out mice that showed reduced learning capabilities, than wild-type mice [91-93]. However, as reported in numerous other studies, TNF- $\alpha$ also has a dark face. It is notably involved in myelin damages [94], in favouring glutamate excitotoxicity [95], in the inhibition of long-term potentiation in the Cornu Ammonis area 1 (CA1) and dentate gyrus of the rat hippocampus, and in decreasing neurogenesis [96-98]. Furthermore, elevated levels of TNF have been described in many neurodegenerative situations such as in Alzheimer's disease (AD), multiple sclerosis (MS), amyotrophic lateral sclerosis (ALS), and PD [99-104].

High levels of TNF- $\alpha$ are found in both CSF and postmortem brain of PD patients and in animal models of PD [104-109] which may indicate that this cytokine acts as a mediator of neuronal damage. To understand the role of 
TNF- $\alpha$ in the neurodegenerative process, genetically modified mouse models were designed, such as knock-out mice lacking TNF- $\alpha$ or TNFR.

Knock-out mice for the TNF- $\alpha$ gene showed a decrease in dopamine content loss in the striatum after administration of 1-methyl-4-phenyl-1,2,3,6-tetrahydropyridine

(MPTP) toxin and no difference in TH-positive cells in the nervous system suggesting a generally detrimental effect of TNF- $\alpha$ on the metabolism of dopamine [110] which is TNFRindependent [111].

However, TNF- $\alpha$ could also play a dual role in PD: neuroprotective during the early stages of the injury and neurotoxic during the chronic phase. In fact, Gemma and colleagues found that if TNF- $\alpha$ was inhibited early, i.e., within one week after administration of 6-OHDA, the inhibition could be neurotoxic; if TNF- $\alpha$ was inhibited late, i.e., 7 to 15 days after administration of 6-OHDA, the inhibition was neuroprotective [112].

Several in vivo reports [113-116] show detrimental effects of TNF- $\alpha$ injection or overexpression on the SN, but adverse results have also been reported, depending on the type, dosage, and administration regimen of TNF- $\alpha$. Acute administration of TNF- $\alpha$ in the SN did not induce degenerative effect [113]. In contrast, in another study in which a much higher dose was administered, loss of dopaminergic cells in the SN at 14 days post inoculation was observed [114].

In experiments where TNF- $\alpha$ is expressed chronically, toxic effects of TNF- $\alpha$ were clearly observed. For instance, rats in which this cytokine was chronically expressed by intranigral injection of an adenoviral vector encoding TNF$\alpha$ had, 14 days after adenoviral inoculation, akinesia of the forelimbs and a distinct inflammatory response in the brain [115]. The subsequent study by Chertoff and coworkers confirms the discovery discussed above; in this experiment, the chronic expression of TNF- $\alpha$ resulted in a progressive loss of dopaminergic (DA) neurons and their terminals in the nervous system and the recruitment of monocytes/macrophages [116].

Taken together, these results indicate that long-term expression of proinflammatory levels of TNF- $\alpha$, or acute but very high expression of this cytokine, appears to be necessary to induce toxic effects on the SN while lower levels have been generating neuroprotection transient against 6OHDA toxicity in the SN and striatum [116].

\section{Physical Exercise in the Rehabilitation of Parkinsonian Subjects and Its Role in Neuroplasticity}

Specific rehabilitation programs, as a support to pharmacological therapies in the treatment of parkinsonian patients, were proposed in 1956 [117]. However, in the beginning, the approaches were based only on empirical experience and there was no attempt to understand the underlying neurological mechanisms. In recent years, the benefits of exercise have been found to be linked to neuroplasticity [18]. To investigate the mechanisms by which exercise induces neuro- plasticity in the mammalian brain, the loss of dopamine cells is induced by targeted injections of MPTP (mouse and nonhuman primate) or 6-OHDA in rats. In both models [118123], physical exercise improves motor performance, including gait speed, step length, and balance.

Studies on the neuroprotective effects of physical exercise introduced forced or voluntary exercise before, during, or immediately after administration of the toxins (6-OHDA or MPTP) and reported improved motor functions, along with the preservation of dopaminergic neurons and the restoration of dopaminergic terminals in the striatum. These improvements have been mainly attributed to either an increased level of neurotrophic factors such as BDNF or GDNF [124-126] or exercise-induced downregulation of the dopamine transporter (DAT) [119, 123]. Other factors affect/modulate the neuroprotective effects of exercise, among which the temporal interval between the lesion and the beginning of the physical training (e.g., exercise started 1 week after toxin administration fails to protect against cell loss [127]) and the extent of toxin-induced damage.

Neurorestoration is suggested as another exerciseinduced process for recovery of behavioural functions, and it does not involve neuroprotection [123]. In fact, neurorestorative effects of exercise are defined as the brain's responses to exercise after the completion of toxin-induced cell death. Studies have shown that exercise increases dopamine release, increases synaptic plasticity, and decreases dopamine clearance by reducing DAT expression [119, 128, 129]. Furthermore, it has been shown that strenuous exercise, on a treadmill, reverses the reduction of dopamine D2 receptors in the dorsal striatum, which usually occurs after injury [118]. Both the restoration of dopamine D2 receptors and the increase in dopamine release are extremely important in the advanced phase of motor learning when automaticity develops [130]. Therefore, both phenomena could contribute to the neuroplastic mechanisms involved in the improvement of exercise-induced motor behaviour and restoration of automaticity.

Physical exercise also modulates glutamatergic neurotransmission. Among the crucial aspects underlying motor impairment in individuals with PD, there is the hyperexcitability in the indirect pathway induced by dopamine depletion in the striatum in response to alterations in glutamate receptor expression and neurotransmitter release [131]. VanLeeuwen and colleagues have shown that strenuous exercise can restore the expression of glutamate receptors, including the $\alpha$-amino-3-hydroxy-5-methyl-4-isoxazolepropionic acid (AMPA) receptors, which are modified in many neurological disease states and are considered a viable target for drug treatment $[132,133]$. In addition to the effects on glutamate receptors, exercise can also alter the storage and release of glutamate in presynaptic terminals, which may also improve circuit function and reduce the increased inhibitory drive of the dopamine-depleted striatum [134-136]. Thus, these findings suggest that exercise, through its effects on neurotransmitters and their receptors, could help restore the neurophysiological properties of synapses within the damaged striatum that are necessary for normal motor learning and motor activity [18]. 
In summary, exercise is generally accepted as an intervention that could help both motor and nonmotor complications of PD, but it should be emphasized that not all types of rehabilitation approaches could facilitate neuroplasticity and behaviour in individuals with PD. Indeed, experiencedependent neuroplasticity is largely dependent on the intensity, repetition, specificity, difficulty, and complexity of the practice, and it is very likely that patients with PD need more time to achieve effective learning and automation. A precedent study by Frazzitta and colleagues [137] demonstrated that the rate of recurrence of physiotherapy sessions (2 daily sessions, 5 days a week for 4 weeks) induces beneficial effects that persist for a follow-up period of 12 months, with a reduced need to increase the doses of Levodopa. This result would suggest that the frequency of rehabilitation intervention is a critical factor, which could influence the natural progression of motor impairment in PD.

The study of Tinazzi and colleagues (2019) based on a four-week trunk-specific exercise program in PD patients with pronounced forward trunk flexion has confirmed the importance of intensive and specific physiotherapy. Rehabilitative protocols lasted 4 weeks ( $60 \mathrm{~min} /$ day, 5 days/week) and have led to improved passive and active control of the trunk that was maintained at one month post treatment [138].

Similarly, Corcos and colleagues [139] reported that progressive resistance exercise improved motor subscale Unified Parkinson's Disease Rating Scale (UPDRS-III) scores in PD patients with an effect lasting up to 2 years. Therefore, it could be hypothesized that the association of periodic intensive rehabilitation courses with pharmacological treatment should be considered one of the best options for the treatment of PD patients. To date, however, there is still a need for a general consensus on which is the best treatment modality (type-frequency-intensity) and on the most significant outcome measures [140].

\subsection{Effects of Exercise on Cytokines and Neurotrophin Levels.} Here, we intend to focus on the effects of exercise on altered levels of proinflammatory cytokines and GDNF and BDNF.

Neurotrophins are a group of proteins having the ability to stimulate survival, cell growth, and maintenance of the functional capacities of specific neuronal populations [141]. Initially, neurotrophins are synthesized as precursor proteins (proneurotrophins) and, because of the involvement of several enzymes, are converted into their mature form and released into the extracellular space [142]. Each of these mature proteins forms a complex with a twin molecule forming a dimeric structure that allows the activation of specific receptors [143]. Neurotrophins act through two types of receptors: tyrosine kinase receptors, with high affinity for mature neurotrophins, and p75 receptors, with low affinity for mature and high affinity for immature forms. Previous studies have suggested that proneurotrophins, through the p75 receptors, exert opposite biological effects with respect to mature proteins, and therefore, the proteolytic cleavage of proneurotrophins may represent a control mechanism that orchestrates the activity of neurotrophins [144]. Furthermore, these proteins are able to self-regulate their production as well as regulate the production of other members of this group of proteins $[145,146]$.

The most studied neurotrophic factors in PD are GDNF and BDNF.

GDNF is a neurotrophic factor purified for the first time from a rat glioma cell line (B49) [147] and belongs together with neurturin (NRTN), artemin (ARTN), and persephin (PSPN) to the family of GDNF ligands (GFL) belonging in turn to the superfamily of transforming growth factor $\beta$ (TGF- $\beta$ ) [148]. In recent years, both the GDNF and the GFL ligands have been investigated due to their involvement in the survival of dopaminergic and noradrenergic neurons. However, GDNF besides acting on dopaminergic neurons promotes the survival of many other neuronal populations including motor and enteric neurons, noradrenergic and serotonergic cell population, and peripheral sensory and autonomic neurons. In addition, GDNF is expressed in brain regions that receive catecholaminergic afferents [149], such as the striatum and thalamus $[150,151]$.

Furthermore, studies performed on rat and mouse models of PD showed the neurorestorative properties of GDNF $[152,153]$. In nonhuman primate PD models, GDNF augmented the sizes of nigral DA neurons that were $20 \%$ larger, with an increased fiber density, and it improved parkinsonian symptoms such as bradykinesia, stiffness, balance, and posture $[154,155]$.

Furthermore, the trophic effects of GDNF have been described as TGF- $\beta$-dependent. Indeed, TGF- $\beta$ acts as a modulator of GDNF signalling and participates in the translocation of GDNF family receptor- $\alpha$ (GFR $\alpha$ ) coreceptors in the cell membrane. The association between ligand and coreceptor forms the GDNF-GFR $\alpha$ complex that can interact with the neural cell adhesion molecule (NCAM) receptors or with a transmembrane tyrosine kinase (RET (REarranged during Transfection)) dimer, inducing their homodimerization and tyrosine autophosphorylation and initiating the intracellular signalling process. Hence, a series of cascades occur, including the activation of the nonreceptor tyrosine kinase Fyn- (Fyn-) focal adhesion kinase- (FAK-) MAPK signalling pathway by the GDNF-GFR $\alpha$-NCAM complex and the activation of the rat sarcoma virus GTP-binding protein(RAS-) MAPK-phosphoinositide 3-kinase (PI3K) signalling pathway by the GDNF-GFR $\alpha$-RET complex $[156,157]$. These cascades play a role in the control of neurite outgrowth [158] and in neuronal growth and survival through the activation of the cAMP response element-binding protein (CREB) and the protein kinase $\mathrm{B}(\mathrm{PKB})$, involved in cell proliferation and transcription $[156,159]$. Furthermore, GDNF also appears to be able to modulate microglia activation through GDNF family receptor $\alpha 1$ (GFR $\alpha 1$ ). Thus, GDNF triggers signalling cascades, which are responsible for inhibiting microglia activation [160].

Because of these promising effects on PD, researchers have investigated several means able to increase GDNF levels.

The direct delivery of GDNF to the brain region affected in PD seems to optimize the chances of obtaining therapeutic efficacy. Using different viral vectors and different animal models including adeno-associated viral vectors (AAV) in 
rat models of PD [161], AAV in nonhuman primates [162], and lentivirus [163] and adenovirus [164] in rats, the neurorestorative effects of GDNF were carefully demonstrated. Although these findings are promising, the results from clinical trials are not very encouraging. For example, a study based on monthly intracerebroventricular injections of GDNF reported no improvement and several side effects [165]. However, another study where GDNF was administered directly into the putamen showed an improvement in motor function as well as an increase in dopamine uptake measured by positron emission tomography (PET) without any side effects [166].

So far, the clinical evaluations of GDNF treatments in patients with PD have been inconsistent, potentially due to insufficient distribution of GDNF throughout the nigrostriatal system [167-169]. In order to increase GDNF nigrostriatal distribution, we conducted a study using an implantable and removable encapsulated cell system able to deliver targeted and long-lasting de novo synthesized high levels of human GDNF into the striatum of 6-OHDA-lesioned rats and Goettingen miniature pig. GDNF was distributed throughout the striatum, and this massive spreading of the protein led to almost complete protection of dopaminergic neurons in the damaged $\mathrm{SN}$ and preservation of $\mathrm{TH}$ positive fibers in the striatum. Furthermore, these same animals demonstrated a slow and steady improvement in motor performance when evaluated on 3 separate neurological tests (cylinder, placing, and stepping tests). Our data demonstrated also that a part of the motor recovery is explained by the germination or regeneration of residual dopaminergic terminals postinjury [170]. Beneficial effects were observed when the same therapeutic approach was investigated into the hippocampus of pilocarpine-treated rats $[171,172]$.

Thus, long-term targeted release of GDNF over the majority of the nigrostriatal system could represent an interesting and attractive option for treatment of PD.

Another valuable ally for increasing GDNF release is physical exercise [125]. A very recent study also highlighted the ability of controlled exercise on a treadmill in mice to increase the striatal content of GDNF as well as normalize striatal levels of tyrosine hydroxylase and attenuate LDOPA-induced dyskinesia (LID [173]), thus providing the first indication that the antidyskinetic effects of exercise may lead to an increase in striatal GDNF levels [174].

The other most studied neurotrophic factor in PD is BDNF. BDNF supports the survival and the differentiation of dopaminergic neurons and protects them from neurotoxin-induced degeneration [175]. Many studies have documented some evidence of a decreased expression of BDNF in different neurodegenerative diseases $[176,177]$. PD patients present lower concentrations of BDNF mRNA and protein in the substantia nigra pars compacta than healthy controls $[178,179]$. On the contrary, some studies reported an increase of BDNF levels in the serum of PD patients, especially in moderate to severe stages of the disease $[180,181]$. This could happen because the CNS to counteract neuronal loss would increase BDNF production resulting in enhanced serum levels of the protein. However, there is no direct evidence that supports this hypothesis. The onset and progression of $\mathrm{PD}$ are also associated with neuroinflammation. Sawada and coworkers have found a notable increase of microglial cells in the hippocampus, amygdala, and entorhinal cortex of PD patients, which was associated with a decrease of BDNF mRNA expression and increased IL-6 in those regions. Moreover, they have also shown increased levels of IL- $1 \beta$, interleukin-2 (IL-2), IL- 6 , and TNF- $\alpha$ in the striatum of PD patients associated with decreased BDNF protein levels in the same structure [182]. However, there is no evidence on how changes in BDNF levels in the brain affect the progression of $\mathrm{PD}$, and further analysis of the interaction between proinflammatory cytokines and BDNF levels is necessary.

A research field in continuous development focuses on studying the effects of exercise on BDNF level changes in healthy adult populations $[183,184]$ and in people affected by neurodegenerative disease $[185,186]$.

Exercise-induced BDNF release seems to carry out a crucial role in neuroplastic effects of rehabilitation interventions in humans with neurodegenerative disease, particularly with PD [183, 187-189], and it is believed that the physiologic mechanisms underlying exercise-induced BDNF changes in PD could include long-term potentiation (LTP) and longterm depression (LTD) mechanisms [190, 191].

In fact, it seems that BDNF plays a complicated role in both LTP and LTD and contributes in different ways to short-term and long-term plasticity: initially, the pro-BDNF binds to two postsynaptic receptors: the tyrosine kinase $\mathrm{B}$ (TrkB) receptor and the $\mathrm{p} 75$ receptor. TrkB activation facilitates the induction of LTP [192] while p75 receptor stimulation modulates the $\mathrm{N}$-methyl-D-aspartate (NMDA) activity that promotes the subsequent induction of LTD [193]. Thus, although its action is particularly complex, BDNF is a major player in synaptic plasticity.

In order to explore if the neuroprotection offered by exercise is BDNF-dependent, Gerecke and colleagues (2010) studied the effectiveness of voluntary physical training with a running wheel in mice on a 90-day program. Mice were divided into two groups: mice with heterozygous deletion of the BDNF gene and wild-type mice. Only the second group showed neuroprotection against exposure to the toxin inducing dopamine cell loss [194]. Researchers also analysed voluntary training in PD mice after periods of 30,60 , or 90 days. The running training for 90 days best promoted a neuroprotective effect on dopaminergic cells showing only a $9 \%$ loss of DA neurons while loss of DA neurons was more consistent in animals that underwent 30 days or 60 days of voluntary training [194].

A different research team has demonstrated that physical exercise reduces the 6-OHDA-induced damage acting on BDNF receptors. In fact, blocking of BDNF receptors causes enhanced postlesion nigrostriatal dopaminergic cell loss, quantified as a reduction in the expression of TH $[126,191]$.

Finally, clinical data on the impact of physical exercise on reducing PD-related proinflammatory cytokine levels received increasing attention over recent years; in particular, investigations focus on the modulation of inflammatory markers as potential molecular mechanisms involved in the beneficial effects of exercise on PD patients. 
Cadet and colleagues showed that cyclical exercise, performed for months, leads to a significant increase in the plasma level of anti-inflammatory signal molecules, such as interleukin-10 (IL-10) and adrenocorticotropin, while plasma levels of proinflammatory cytokines such as IL-1 and IL-6 were not affected. Additionally, this cyclic exercise protocol has also been shown to improve fine motor skills. These data suggest that cyclical exercise induces the formation of anti-inflammatory signalling molecules, which appear to be associated with relieving of some clinical impairments of PD [195].

Two more recent studies (years 2017 and 2018) also showed that alternative and not traditional physical exercises such as Qigong, an oriental mind-body exercise, or physical exercise in water can improve the inflammatory state of PD.

In this study by Moon and colleagues, ten subjects with PD were recruited and then randomly assigned to one of the two groups who received six weeks of Qigong intervention (experimental group) or sham Qigong (control group). After the intervention, the serum level of TNF- $\alpha$ in the experimental group was significantly reduced in all subjects, and there is a stabilized sleep pattern suggesting that TNF- $\alpha$ can potentially affect sleep quality in people with PD [196].

Pochmann and colleagues instead focused on exploring the molecular mechanisms underlying the improvement of motor symptoms and functional mobility in water-based exercise interventions in patients with $\mathrm{PD}$. The authors reported higher levels of the proinflammatory cytokines IL$1 \beta$ and MCP-1 in patients with Parkinson's compared to the control group and a reduction in the levels of these proinflammatory cytokines after an aquatic physiotherapy program for 1 month, two times a week $(60 \mathrm{~min} / \mathrm{session})$. These data support the idea that the inflammatory state is linked to PD and that proinflammatory cytokines could be considered promising biomarkers for the diagnosis and progression of this condition [197].

\section{Conclusion}

In conclusion, both traditional and not traditional forms of exercise have been shown to be important for improving motor function, facilitating neuroplasticity, and reducing neuroinflammation in PD. Further investigations are needed to broaden our knowledge on the mechanisms through which specific physical training induces neuroplasticity, eventually leading to a deeper knowledge of its role in interfering with the disease progression and to identify novel therapeutic targets to finally improve the effects of pharmacological approaches of $\mathrm{PD}$.

\section{Abbreviations}

$\mathrm{AD}$ :

ALS:

AMPA receptors:
Alzheimer's disease

Amyotrophic lateral

sclerosis

$\alpha$-Amino-3-hydroxy-5methyl-4-isoxazolepropionic acid receptors

ARTN:
AVV:

BBB:

BDNF:

BMECs:

CA1:

CNS:

CREB:

CSF:

DA neurons:

DAT:

ERK:

FAK:

Fyn:

GDNF:

GFR $\alpha$ :

GFR $\alpha 1$ :

GFL:

JAK/STAT signalling pathway:

IFN- $\gamma$ :

IL- $1 \beta$ :

IL-2:

IL-6:

IL-8:

IL-10:

LID:

LPS:

LTD:

LTP:

MAPK:

MCP-1:

MPTP:

MS:

NCAM receptors:

NMDA:

NRTN:

6-OHDA:

PI3K:

RNS:

ROS:

SN:

PD:

PET:

PKB:
Adeno-associated viral vectors

Blood-brain barrier

Brain-derived neurotrophic factor

Brain microvascular endo-

thelial cells

Cornu Ammonis area 1

Central nervous system

cAMP response element-

binding protein

Cerebrospinal fluid

Dopaminergic neurons

Dopamine transporter

Extracellular signal-

regulated kinase

Focal adhesion kinase

Nonreceptor tyrosine

kinase Fyn

Glial cell line-derived neurotrophic factor

GDNF family receptor- $\alpha$

GDNF family receptor $\alpha 1$

GDNF family

Janus kinase- (JAK-) signal transducer and activator of transcription (STAT)

Interferon- $\gamma$

Interleukin- $1 \beta$

Interleukin-2

Interleukin-6

Interleukin-8

Interleukin-10

L-DOPA-induced

dyskinesia

Lipopolysaccharide

Long-term depression

Long-term potentiation

Mitogen-activated protein

kinase

Monocyte chemotactic pro-

tein-1

1-Methyl-4-phenyl-1,2,3,6-

tetrahydropyridine

Multiple sclerosis

Neural cell adhesion mole-

cule receptors

$\mathrm{N}$-Methyl-D-aspartate

receptor

Neurturin

6-Hydroxy dopamine

Phosphoinositide 3-kinase

Reactive nitrogen species

Reactive oxygen species

Substantia nigra

Parkinson's disease

Positron emission

tomography

Protein kinase B 


$\begin{array}{ll}\text { PSPN: } & \text { Persephin } \\ \text { RAS: } & \begin{array}{l}\text { Rat sarcoma virus GTP- } \\ \text { binding protein } \\ \text { REarranged during } \\ \text { RET: }\end{array} \\ \text { Transfection } \\ \text { TGF- } \beta \text { Transforming growth factor } \\ \text { TH: } & \beta \\ \text { TNF- } \alpha: & \text { Tyrosine hydroxylase } \\ \text { TrkB: } & \text { Tumor necrosis factor- } \alpha \\ \text { UPDRS-III score: } & \text { Tyrosine kinase B } \\ & \text { Unified Parkinson's Disease } \\ & \text { Rating Scale score. }\end{array}$

\section{Conflicts of Interest}

The authors declare that the research was conducted in the absence of any commercial or financial relationships that could be construed as a potential conflict of interest.

\section{Acknowledgments}

The study was supported by the University of Verona Basic Research Grant, awarded to Giovanna Paolone Grant ID: RIBA 2019.

\section{References}

[1] W. Poewe, K. Seppi, C. M. Tanner et al., "Parkinson disease," Nature Reviews. Disease Primers, vol. 3, no. 1, p. 17013, 2017.

[2] G. Paolone, "From the gut to the brain and back: therapeutic approaches for the treatment of network dysfunction in Parkinson's disease," Frontiers in Neurology, vol. 11, p. 557928, 2020.

[3] A. Kucinski, G. Paolone, M. Bradshaw, R. L. Albin, and M. Sarter, "Modeling fall propensity in Parkinson's disease: deficits in the attentional control of complex movements in rats with cortical-cholinergic and striatal-dopaminergic deafferentation," The Journal of Neuroscience, vol. 33, no. 42, pp. 16522-16539, 2013.

[4] A. McKinlay, R. C. Grace, J. C. Dalrymple-Alford, T. Anderson, J. Fink, and D. Roger, "A profile of neuropsychiatric problems and their relationship to quality of life for Parkinson's disease patients without dementia," Parkinsonism \& Related Disorders, vol. 14, no. 1, pp. 37-42, 2008.

[5] M. S. Moehle and A. B. West, "M1 and M2 immune activation in Parkinson's disease: foe and ally?," Neuroscience, vol. 302, pp. 59-73, 2015.

[6] R. M. Ransohoff, "How neuroinflammation contributes to neurodegeneration," Science, vol. 353, no. 6301, pp. 777783, 2016.

[7] P. L. McGeer, S. Itagaki, H. Akiyama, and E. G. McGeer, "Rate of cell death in parkinsonism indicates active neuropathological process," Annals of Neurology, vol. 24, no. 4, pp. 574-576, 1988.

[8] R. M. Ransohoff and V. H. Perry, "Microglial physiology: unique stimuli, specialized responses," Annual Review of Immunology, vol. 27, no. 1, pp. 119-145, 2009.

[9] R. Divella, R. De Luca, I. Abbate, E. Naglieri, and A. Daniele, "Obesity and cancer: the role of adipose tissue and adipocytokines-induced chronic inflammation," Journal of Cancer, vol. 7, no. 15, pp. 2346-2359, 2016.
[10] I. A. Arnoldussen, A. J. Kiliaan, and D. R. Gustafson, "Obesity and dementia: adipokines interact with the brain," European Neuropsychopharmacology, vol. 24, no. 12, pp. 1982-1999, 2014.

[11] P. M. Carvey, B. Hendey, and A. J. Monahan, "The bloodbrain barrier in neurodegenerative disease: a rhetorical perspective," Journal of Neurochemistry, vol. 111, no. 2, pp. 291-314, 2009.

[12] C. Rosano, A. L. Marsland, and P. J. Gianaros, "Maintaining brain health by monitoring inflammatory processes: a mechanism to promote successful aging," Aging and Disease, vol. 3, no. 1, pp. 16-33, 2012.

[13] A. J. Dunn and A. H. Swiergiel, "The role of cytokines in infection-related Behaviora," Annals of the New York Academy of Sciences, vol. 840, no. 1, pp. 577-585, 1998.

[14] J. Serrats, J. C. Schiltz, B. García-Bueno, N. van Rooijen, T. M. Reyes, and P. E. Sawchenko, "Dual roles for perivascular macrophages in immune-to-brain signaling," Neuron, vol. 65, no. 1, pp. 94-106, 2010.

[15] S. Liebner, R. M. Dijkhuizen, Y. Reiss, K. H. Plate, D. Agalliu, and G. Constantin, "Functional morphology of the bloodbrain barrier in health and disease," Acta Neuropathologica, vol. 135, no. 3, pp. 311-336, 2018.

[16] S. L. Patterson, "Immune dysregulation and cognitive vulnerability in the aging brain: interactions of microglia, IL- $1 \beta$, BDNF and synaptic plasticity," Neuropharmacology, vol. 96, no. Part A, pp. 11-18, 2015.

[17] M. Pedrazzoli, M. Losurdo, G. Paolone et al., "Glucocorticoid receptors modulate dendritic spine plasticity and microglia activity in an animal model of Alzheimer's disease," Neurobiology of Disease, vol. 132, p. 104568, 2019.

[18] G. M. Petzinger, B. E. Fisher, S. McEwen, J. A. Beeler, J. P. Walsh, and M. W. Jakowec, "Exercise-enhanced neuroplasticity targeting motor and cognitive circuitry in Parkinson's disease," Lancet Neurology, vol. 12, no. 7, pp. 716-726, 2013.

[19] M. G. Tansey, T. C. Frank-Cannon, M. K. McCoy et al., "Neuroinflammation in Parkinson's disease: is there sufficient evidence for mechanism-based interventional therapy?," Frontiers in Bioscience, vol. 13, no. 13, pp. 709-717, 2008.

[20] M. G. Netea, C. A. Nold-Petry, M. F. Nold et al., "Differential requirement for the activation of the inflammasome for processing and release of IL-1beta in monocytes and macrophages," Blood, vol. 113, no. 10, pp. 2324-2335, 2009.

[21] E. Hoffmann, A. Thiefes, D. Buhrow et al., "MEK1-dependent delayed expression of Fos-related antigen-1 counteracts $\mathrm{c}-\mathrm{Fos}$ and $\mathrm{p} 65 \mathrm{NF}-\kappa \mathrm{B}$-mediated interleukin- 8 transcription in response to cytokines or growth factors," The Journal of Biological Chemistry, vol. 280, no. 10, pp. 9706-9718, 2005.

[22] O. Bandman, R. T. Coleman, J. F. Loring, J. J. Seilhamer, and B. G. Cocks, "Complexity of inflammatory responses in endothelial cells and vascular smooth muscle cells determined by microarray analysis," Annals of the New York Academy of Sciences, vol. 975, no. 1, pp. 77-90, 2002.

[23] C. A. Dinarello, "Interleukin-1 in the pathogenesis and treatment of inflammatory diseases," Blood, vol. 117, no. 14, pp. 3720-3732, 2011.

[24] S. J. Hewett, N. A. Jackman, and R. J. Claycomb, "Interleukinlbeta in central nervous system injury and repair," European journal of neurodegenerative disease, vol. 1, no. 2, pp. 195$211,2012$. 
[25] W. A. Banks and A. J. Kastin, "Blood to brain transport of interleukin links the immune and central nervous systems," Life sciences, vol. 48, no. 25, pp. PL117-PL121, 1991.

[26] D. Giulian, T. J. Baker, L. C. Shih, and L. B. Lachman, "Interleukin 1 of the central nervous system is produced by ameboid microglia," The Journal of Experimental Medicine, vol. 164, no. 2, pp. 594-604, 1986.

[27] J. Yao, J. E. Keri, R. E. Taffs, and C. A. Colton, "Characterization of interleukin-1 production by microglia in culture," Brain Research, vol. 591, no. 1, pp. 88-93, 1992.

[28] E. Pinteaux, L. C. Parker, N. J. Rothwell, and G. N. Luheshi, "Expression of interleukin-1 receptors and their role in interleukin-1 actions in murine microglial cells," Journal of Neurochemistry, vol. 83, no. 4, pp. 754-763, 2002.

[29] F. Knerlich, L. Schilling, C. Görlach, M. Wahl, H. Ehrenreich, and A. L. Sirén, "Temporal profile of expression and cellular localization of inducible nitric oxide synthase, interleukin1 beta and interleukin converting enzyme after cryogenic lesion of the rat parietal cortex," Brain Research. Molecular Brain Research, vol. 68, no. 1-2, pp. 73-87, 1999.

[30] F. Blasi, M. Riccio, A. Brogi et al., "Constitutive expression of interleukin-1beta (IL-1beta) in rat oligodendrocytes," Biological Chemistry, vol. 380, no. 2, pp. 259-264, 1999.

[31] J. A. Watt and N. K. Hobbs, "Interleukin-1beta immunoreactivity in identified neurons of the rat magnocellular neurosecretory system: evidence for activity-dependent release," Journal of Neuroscience Research, vol. 60, no. 4, pp. 478$489,2000$.

[32] W. J. Friedman, "Cytokines regulate expression of the type 1 interleukin-1 receptor in rat hippocampal neurons and glia," Experimental Neurology, vol. 168, no. 1, pp. 23-31, 2001.

[33] D. M. Juric and M. Carman-Krzan, "Interleukin-1 beta, but not IL-1 alpha, mediates nerve growth factor secretion from rat astrocytes via type I IL-1 receptor," International Journal of Developmental Neuroscience, vol. 19, no. 7, pp. 675-683, 2001.

[34] T. Miyachi, K. Asai, H. Tsuiki et al., "Interleukin-1beta induces the expression of lipocortin 1 mRNA in cultured rat cortical astrocytes," Neuroscience Research, vol. 40, no. 1, pp. 53-60, 2001.

[35] M. Mogi, M. Harada, T. Kondo et al., "Interleukin-1 beta, interleukin-6, epidermal growth factor and transforming growth factor-alpha are elevated in the brain from parkinsonian patients," Neuroscience Letters, vol. 180, no. 2, pp. 147150, 1994.

[36] C. C. Ferrari, M. C. Godoy, R. Tarelli, M. Chertoff, A. M. Depino, and F. J. Pitossi, "Progressive neurodegeneration and motor disabilities induced by chronic expression of ILlbeta in the substantia nigra," Neurobiology of Disease, vol. 24, no. 1, pp. 183-193, 2006.

[37] M. C. Pott Godoy, C. C. Ferrari, and F. J. Pitossi, "Nigral neurodegeneration triggered by striatal AdIL-1 administration can be exacerbated by systemic IL-1 expression," Journal of Neuroimmunology, vol. 222, no. 1-2, pp. 29-39, 2010.

[38] M. C. Pott Godoy, R. Tarelli, C. C. Ferrari, M. I. Sarchi, and F. J. Pitossi, "Central and systemic IL-1 exacerbates neurodegeneration and motor symptoms in a model of Parkinson's disease," Brain, vol. 131, no. 7, pp. 1880-1894, 2008.

[39] J. B. Koprich, C. Reske-Nielsen, P. Mithal, and O. Isacson, "Neuroinflammation mediated by IL- $1 \beta$ increases susceptibility of dopamine neurons to degeneration in an animal model of Parkinson's disease," Journal of Neuroinflammation, vol. 5, no. 1, p. 8, 2008.

[40] J. Saura, M. Parés, J. Bové et al., "Intranigral infusion of interleukin-1beta activates astrocytes and protects from subsequent 6-hydroxydopamine neurotoxicity," Journal of Neurochemistry, vol. 85, no. 3, pp. 651-661, 2003.

[41] D. L. Gruol and T. E. Nelson, "Physiological and pathological roles of interleukin-6 in the central nervous system," Molecular Neurobiology, vol. 15, no. 3, pp. 307-339, 1997.

[42] R. A. Gadient and U. H. Otten, "Interleukin-6 (IL-6)-a molecule with both beneficial and destructive potentials," Progress in Neurobiology, vol. 52, no. 5, pp. 379-390, 1997.

[43] T. Müller, D. Blum-Degen, H. Przuntek, and W. Kuhn, "Interleukin-6 levels in cerebrospinal fluid inversely correlate to severity of Parkinson's disease," Acta Neurologica Scandinavica, vol. 98, no. 2, pp. 142-144, 1998.

[44] H. Bessler, R. Djaldetti, H. Salman, M. Bergman, and M. Djaldetti, "IL-1 beta, IL-2, IL-6 and TNF-alpha production by peripheral blood mononuclear cells from patients with Parkinson's disease," Biomedicine \& Pharmacotherapy, vol. 53, no. 3, pp. 141-145, 1999.

[45] B. Brodacki, J. Staszewski, B. Toczyłowska et al., "Serum interleukin (IL-2, IL-10, IL-6, IL-4), TNF $\alpha$, and INF $\gamma$ concentrations are elevated in patients with atypical and idiopathic parkinsonism," Neuroscience Letters, vol. 441, no. 2, pp. 158-162, 2008.

[46] I. L. Campbell, M. Erta, S. L. Lim et al., "Trans-signaling is a dominant mechanism for the pathogenic actions of interleukin-6 in the brain," The Journal of Neuroscience, vol. 34, no. 7, pp. 2503-2513, 2014.

[47] H. Hirota, H. Kiyama, T. Kishimoto, and T. Taga, "Accelerated nerve regeneration in mice by upregulated expression of interleukin (IL) 6 and IL-6 receptor after trauma," The Journal of Experimental Medicine, vol. 183, no. 6, pp. 26272634, 1996.

[48] P. Yang, H. Wen, S. Ou, J. Cui, and D. Fan, "IL-6 promotes regeneration and functional recovery after cortical spinal tract injury by reactivating intrinsic growth program of neurons and enhancing synapse formation," Experimental Neurology, vol. 236, no. 1, pp. 19-27, 2012.

[49] T. Nakajima, S. Kinoshita, T. Sasagawa et al., "Phosphorylation at threonine- 235 by a ras-dependent mitogen-activated protein kinase cascade is essential for transcription factor NF-IL6," Proceedings of the National Academy of Sciences of the United States of America, vol. 90, no. 6, pp. 2207-2211, 1993.

[50] P. C. Heinrich, I. Behrmann, G. Müller-Newen, F. Schaper, and L. Graeve, "Interleukin-6-type cytokine signalling through the gp130/Jak/STAT pathway," The Biochemical Journal, vol. 334, no. 2, pp. 297-314, 1998.

[51] T. Kishimoto, S. Akira, M. Narazaki, and T. Taga, "Interleukin-6 family of cytokines and gp130," Blood, vol. 86, no. 4, pp. 1243-1254, 1995.

[52] J. Bauer, T. M. Bauer, T. Kalb et al., "Regulation of interleukin 6 receptor expression in human monocytes and monocytederived macrophages. Comparison with the expression in human hepatocytes," The Journal of Experimental Medicine, vol. 170, no. 5, pp. 1537-1549, 1989.

[53] M. Narazaki, K. Yasukawa, T. Saito et al., "Soluble forms of the interleukin-6 signal-transducing receptor component gp130 in human serum possessing a potential to inhibit 
signals through membrane-anchored gp130," Blood, vol. 82, no. 4, pp. 1120-1126, 1993.

[54] T. Jostock, J. Müllberg, S. Özbek et al., "Soluble gp130 is the natural inhibitor of soluble interleukin-6 receptor transsignaling responses," European Journal of Biochemistry, vol. 268, no. 1, pp. 160-167, 2001.

[55] M. Peters, P. Schirmacher, J. Goldschmitt et al., "Extramedullary expansion of hematopoietic progenitor cells in interleukin (IL)-6-sIL-6R double transgenic mice," The Journal of Experimental Medicine, vol. 185, no. 4, pp. 755-766, 1997.

[56] C. Becker, M. C. Fantini, C. Schramm et al., "TGF-beta suppresses tumor progression in colon cancer by inhibition of IL-6 trans-signaling," Immunity, vol. 21, no. 4, pp. 491-501, 2004.

[57] R. Atreya, J. Mudter, S. Finotto et al., "Blockade of interleukin 6 trans signaling suppresses T-cell resistance against apoptosis in chronic intestinal inflammation: evidence in crohn disease and experimental colitis in vivo," Nature Medicine, vol. 6, no. 5, pp. 583-588, 2000.

[58] M. Rothaug, C. Becker-Pauly, and S. Rose-John, "The role of interleukin-6 signaling in nervous tissue," Biochimica et Biophysica Acta (BBA)-Molecular Cell Research, vol. 1863, no. 6, pp. 1218-1227, 2016.

[59] T. Nagatsu, "Parkinson's disease: changes in apoptosisrelated factors suggesting possible gene therapy," Journal of Neural Transmission (Vienna), vol. 109, no. 5-6, pp. 731745, 2002.

[60] D. Blum-Degena, T. Müller, W. Kuhn, M. Gerlach, H. Przuntek, and P. Riederer, "Interleukin- $1 \beta$ and interleukin-6 are elevated in the cerebrospinal fluid of Alzheimer's and de novo Parkinson's disease patients," Neuroscience Letters, vol. 202, no. 1-2, pp. 17-20, 1995.

[61] G. Stypuła, J. Kunert-Radek, H. Stępień, K. Żylińska, and M. Pawlikowski, "Evaluation of interleukins, ACTH, cortisol and prolactin concentrations in the blood of patients with parkinson's disease," Neuroimmunomodulation, vol. 3, no. 2-3, pp. 131-134, 2004.

[62] M. V. Selikhova, N. E. Kushlinskii, N. V. Lyubimova, and E. I. Gusev, "Impaired production of plasma interleukin-6 in patients with Parkinson's disease," Bulletin of Experimental Biology and Medicine, vol. 133, no. 1, pp. 81-83, 2002.

[63] T. Yoshimura, K. Matsushima, S. Tanaka et al., "Purification of a human monocyte-derived neutrophil chemotactic factor that has peptide sequence similarity to other host defense cytokines," Proceedings of the National Academy of Sciences of the United States of America, vol. 84, no. 24, pp. 92339237, 1987.

[64] J. Apostolopoulos, P. Davenport, and P. G. Tipping, "Interleukin-8 production by macrophages from atheromatous plaques," Arteriosclerosis, Thrombosis, and Vascular Biology, vol. 16, no. 8, pp. 1007-1012, 1996.

[65] R. M. Strieter, S. Kunkel, H. Showell et al., "Endothelial cell gene expression of a neutrophil chemotactic factor by TNFalpha, LPS, and IL-1 beta," Science, vol. 243, no. 4897, pp. 1467-1469, 1989.

[66] M. Galindo, B. Santiago, J. Alcami, M. Rivero, J. Martín-Serrano, and J. L. Pablos, "Hypoxia induces expression of the chemokines monocyte chemoattractant protein-1 (MCP-1) and IL-8 in human dermal fibroblasts," Clinical and Experimental Immunology, vol. 123, no. 1, pp. 36-41, 2001.
[67] C. C. Lan, C. S. Wu, S. M. Huang, I. H. Wu, and G. S. Chen, "High-glucose environment enhanced oxidative stress and increased interleukin-8 secretion from keratinocytes: new insights into impaired diabetic wound healing," Diabetes, vol. 62, no. 7, pp. 2530-2538, 2013.

[68] E. C. Shin, Y. H. Choi, J. S. Kim, S. J. Kim, and J. H. Park, "Expression patterns of cytokines and chemokines genes in human hepatoma cells," Yonsei Medical Journal, vol. 43, no. 5, pp. 657-664, 2002.

[69] S. Y. Hwang, J. Y. Kim, K. W. Kim et al., "IL-17 induces production of IL-6 and IL-8 in rheumatoid arthritis synovial fibroblasts via NF-kappaB- and PI3-kinase/Akt-dependent pathways," Arthritis Research \& Therapy, vol. 6, no. 2, pp. R120-R128, 2004.

[70] R. Gomez, M. Scotece, J. Conde, J. J. Gomez-Reino, F. Lago, and O. Gualillo, "Adiponectin and leptin increase IL-8 production in human chondrocytes," Annals of the Rheumatic Diseases, vol. 70, no. 11, pp. 2052-2054, 2011.

[71] M. E. Hammond, G. R. Lapointe, P. H. Feucht et al., "IL-8 induces neutrophil chemotaxis predominantly via type I IL8 receptors," Journal of Immunology, vol. 155, no. 3, pp. 1428-1433, 1995.

[72] J. G. McLarnon, "Microglial chemotactic signaling factors in Alzheimer's disease," American Journal of Neurodegenerative Disease, vol. 1, no. 3, pp. 199-204, 2012.

[73] D. Koziorowski, R. Tomasiuk, S. Szlufik, and A. Friedman, "Inflammatory cytokines and NT-proCNP in Parkinson's disease patients," Cytokine, vol. 60, no. 3, pp. 762-766, 2012.

[74] V. Gupta, R. K. Garg, and S. Khattri, "Levels of IL-8 and TNF$\alpha$ decrease in Parkinson's disease," Neurological Research, vol. 38, no. 2, pp. 98-102, 2016.

[75] G. Banisadr, F. Quéraud-Lesaux, M. C. Boutterin et al., "Distribution, cellular localization and functional role of CCR2 chemokine receptors in adult rat brain," Journal of Neurochemistry, vol. 81, no. 2, pp. 257-269, 2002.

[76] S. Ge, L. Song, D. R. Serwanski, W. A. Kuziel, and J. S. Pachter, "Transcellular transport of CCL2 across brain microvascular endothelial cells," Journal of Neurochemistry, vol. 104, no. 5, pp. 1219-1232, 2008.

[77] G. Conductier, N. Blondeau, A. Guyon, J. L. Nahon, and C. Rovère, "The role of monocyte chemoattractant protein MCP1/CCL2 in neuroinflammatory diseases," Journal of Neuroimmunology, vol. 224, no. 1-2, pp. 93-100, 2010.

[78] G. Banisadr, R. D. Gosselin, P. Mechighel, P. Kitabgi, W. Rostène, and S. M. Parsadaniantz, "Highly regionalized neuronal expression of monocyte chemoattractant protein-1 (MCP-1/CCL2) in rat brain: evidence for its colocalization with neurotransmitters and neuropeptides," The Journal of Comparative Neurology, vol. 489, no. 3, pp. 275-292, 2005.

[79] W. Rostene, P. Kitabgi, and S. M. Parsadaniantz, "Chemokines: a new class of neuromodulator?," Nature Reviews Neuroscience, vol. 8, no. 11, pp. 895-903, 2007.

[80] Y. Yao and S. E. Tsirka, "Truncation of monocyte chemoattractant protein 1 by plasmin promotes blood-brain barrier disruption," Journal of Cell Science, vol. 124, no. 9, pp. 1486-1495, 2011.

[81] O. B. Dimitrijevic, S. M. Stamatovic, R. F. Keep, and A. V. Andjelkovic, "Effects of the chemokine CCL2 on bloodbrain barrier permeability during ischemia-reperfusion injury," Journal of Cerebral Blood Flow and Metabolism, vol. 26, no. 6, pp. 797-810, 2005. 
[82] Y. Yao and S. E. Tsirka, "The CCL2-CCR2 system affects the progression and clearance of intracerebral hemorrhage," Glia, vol. 60, no. 6, pp. 908-918, 2012.

[83] M. Reale, C. Iarlori, A. Thomas et al., "Peripheral cytokines profile in Parkinson's disease," Brain, Behavior, and Immunity, vol. 23, no. 1, pp. 55-63, 2009.

[84] E. Gonzalez, B. H. Rovin, L. Sen et al., "HIV-1 infection and AIDS dementia are influenced by a mutant MCP-1 allele linked to increased monocyte infiltration of tissues and MCP-1 levels," Proceedings of the National Academy of Sciences of the United States of America, vol. 99, no. 21, pp. 13795-13800, 2002.

[85] M. Nishimura, S. Kuno, I. Mizuta et al., "Influence of monocyte chemoattractant protein 1 gene polymorphism on age at onset of sporadic Parkinson's disease," Movement Disorders, vol. 18, no. 8, pp. 953-955, 2003.

[86] E. S. Lein, M. J. Hawrylycz, N. Ao et al., "Genome-wide atlas of gene expression in the adult mouse brain," Nature, vol. 445, no. 7124, pp. 168-176, 2007.

[87] S. L. Montgomery and W. J. Bowers, "Tumor necrosis factoralpha and the roles it plays in homeostatic and degenerative processes within the central nervous system," Journal of Neuroimmune Pharmacology, vol. 7, no. 1, pp. 42-59, 2012.

[88] M. Pickering, D. Cumiskey, and J. J. O'Connor, "Actions of TNF-alpha on glutamatergic synaptic transmission in the central nervous system," Experimental Physiology, vol. 90, no. 5, pp. 663-670, 2005.

[89] L. Probert, "TNF and its receptors in the CNS: the essential, the desirable and the deleterious effects," Neuroscience, vol. 302, pp. 2-22, 2015.

[90] S. W. Barger, D. Horster, K. Furukawa, Y. Goodman, J. Krieglstein, and M. P. Mattson, "Tumor necrosis factors alpha and beta protect neurons against amyloid betapeptide toxicity: evidence for involvement of a kappa Bbinding factor and attenuation of peroxide and $\mathrm{Ca} 2+\mathrm{accu}-$ mulation," Proceedings of the National Academy of Sciences of the United States of America, vol. 92, no. 20, pp. 93289332, 1995.

[91] E. C. Beattie, D. Stellwagen, W. Morishita et al., "Control of synaptic strength by glial TNFalpha," Science, vol. 295, no. 5563, pp. 2282-2285, 2002.

[92] L. Marchetti, M. Klein, K. Schlett, K. Pfizenmaier, and U. L. M. Eisel, "Tumor necrosis factor (TNF)-mediated neuroprotection against glutamate-induced excitotoxicity is enhanced by $\mathrm{N}$-methyl-D-aspartate receptor activation. Essential role of a TNF receptor 2-mediated phosphatidylinositol 3kinase-dependent NF-kappa B pathway," The Journal of Biological Chemistry, vol. 279, no. 31, pp. 32869-32881, 2004.

[93] B. T. Baune, F. Wiede, A. Braun, J. Golledge, V. Arolt, and H. Koerner, "Cognitive dysfunction in mice deficient for TNF- and its receptors," American Journal of Medical Genetics. Part B, Neuropsychiatric Genetics, vol. 147B, no. 7, pp. 1056-1064, 2008.

[94] K. Selmaj and C. S. Raine, "Tumor necrosis factor mediates myelin damage in organotypic cultures of nervous tissue," Annals of the New York Academy of Sciences, vol. 540, no. 1 Advances in N, pp. 568-570, 1988.

[95] G. E. Hermann, R. C. Rogers, J. C. Bresnahan, and M. S. Beattie, "Tumor necrosis factor-alpha induces cFOS and strongly potentiates glutamate-mediated cell death in the rat spinal cord," Neurobiology of Disease, vol. 8, no. 4, pp. 590-599, 2001.
[96] M. P. Butler, J. J. O'Connor, and P. N. Moynagh, "Dissection of tumor-necrosis factor-alpha inhibition of long-term potentiation (LTP) reveals a p38 mitogen-activated protein kinase-dependent mechanism which maps to early-but not late-phase LTP," Neuroscience, vol. 124, no. 2, pp. 319-326, 2004.

[97] A. J. Cunningham, C. A. Murray, L. A. J. O'Neill, M. A. Lynch, and J. J. O'Connor, "Interleukin-1 beta (IL-1 beta) and tumour necrosis factor (TNF) inhibit long-term potentiation in the rat dentate gyrus in vitro," Neuroscience Letters, vol. 203, no. 1, pp. 17-20, 1996.

[98] R. E. Iosif, C. T. Ekdahl, H. Ahlenius et al., "Tumor necrosis factor receptor 1 is a negative regulator of progenitor proliferation in adult hippocampal neurogenesis," The Journal of Neuroscience, vol. 26, no. 38, pp. 9703-9712, 2006.

[99] H. Fillit, W. Ding, L. Buee et al., "Elevated circulating tumor necrosis factor levels in Alzheimer's disease," Neuroscience Letters, vol. 129, no. 2, pp. 318-320, 1991.

[100] A. Álvarez, R. Cacabelos, C. Sanpedro, M. García-Fantini, and M. Aleixandre, "Serum TNF-alpha levels are increased and correlate negatively with free IGF-I in Alzheimer disease," Neurobiology of Aging, vol. 28, no. 4, pp. 533-536, 2007.

[101] P. Rieckmann, M. Albrecht, B. Kitze et al., "Tumor necrosis factor-alpha messenger RNA expression in patients with relapsing-remitting multiple sclerosis is associated with disease activity," Annals of Neurology, vol. 37, no. 1, pp. 82-88, 1995.

[102] M. Poloni, D. Facchetti, R. Mai et al., "Circulating levels of tumour necrosis factor- $\alpha$ and its soluble receptors are increased in the blood of patients with amyotrophic lateral sclerosis," Neuroscience Letters, vol. 287, no. 3, pp. 211-214, 2000.

[103] G. N. Babu, A. Kumar, R. Chandra, S. K. Puri, J. Kalita, and U. K. Misra, "Elevated inflammatory markers in a group of amyotrophic lateral sclerosis patients from northern India," Neurochemical Research, vol. 33, no. 6, pp. 1145-1149, 2008.

[104] G. Boka, P. Anglade, D. Wallach, F. Javoy-Agid, Y. Agid, and E. C. Hirsch, "Immunocytochemical analysis of tumor necrosis factor and its receptors in Parkinson's disease," Neuroscience Letters, vol. 172, no. 1-2, pp. 151-154, 1994.

[105] S. Hunot, N. Dugas, B. Faucheux et al., "FcepsilonRII/CD23 is expressed in Parkinson's disease and induces, in vitro, production of nitric oxide and tumor necrosis factor-alpha in glial cells," The Journal of Neuroscience, vol. 19, no. 9, pp. 3440-3447, 1999.

[106] M. Mogi, A. Togari, K. I. Tanaka, N. Ogawa, H. Ichinose, and T. Nagatsu, "Increase in level of tumor necrosis factor-alpha in 6-hydroxydopamine-lesioned striatum in rats is suppressed by immunosuppressant FK506," Neuroscience Letters, vol. 289, no. 3, pp. 165-168, 2000.

[107] K. Sriram, J. M. Matheson, S. A. Benkovic, D. B. Miller, M. I. Luster, and J. P. O'Callaghan, "Mice deficient in TNF receptors are protected against dopaminergic neurotoxicity: implications for Parkinson's disease," The FASEB Journal, vol. 16, no. 11, pp. 1474-1476, 2002.

[108] C. Barcia, V. . Pablos, V. Bautista-Hernández et al., "Increased plasma levels of TNF-alpha but not of IL1-beta in MPTP-treated monkeys one year after the MPTP administration," Parkinsonism \& Related Disorders, vol. 11, no. 7, pp. 435-439, 2005. 
[109] T. Nagatsu and M. Sawada, "Inflammatory process in Parkinson's disease: role for cytokines," Current Pharmaceutical Design, vol. 11, no. 8, pp. 999-1016, 2005.

[110] B. Ferger, A. Leng, A. Mura, B. Hengerer, and J. Feldon, "Genetic ablation of tumor necrosis factor-alpha (TNFalpha) and pharmacological inhibition of TNF-synthesis attenuates MPTP toxicity in mouse striatum," Journal of Neurochemistry, vol. 89, no. 4, pp. 822-833, 2004.

[111] A. Leng, A. Mura, J. Feldon, and B. Ferger, "Tumor necrosis factor-alpha receptor ablation in a chronic MPTP mouse model of Parkinson's disease," Neuroscience Letters, vol. 375, no. 2, pp. 107-111, 2005.

[112] C. Gemma, B. Catlow, M. Cole et al., "Early inhibition of TNF $\alpha$ increases 6-hydroxydopamine-induced striatal degeneration," Brain Research, vol. 1147, pp. 240-247, 2007.

[113] A. Castaño, A. J. Herrera, J. Cano, and A. Machado, "The degenerative effect of a single intranigral injection of LPS on the dopaminergic system is prevented by dexamethasone, and not mimicked by rh-TNF- $\alpha$, IL- $1 \beta$ and IFN- $\gamma$," Journal of Neurochemistry, vol. 81, no. 1, pp. 150-157, 2002.

[114] P. M. Carvey, C. H. Zhao, B. Hendey et al., "6-Hydroxydopamine-induced alterations in blood-brain barrier permeability," The European Journal of Neuroscience, vol. 22, no. 5, pp. 1158-1168, 2005.

[115] A. L. de Lella Ezcurra, M. Chertoff, C. Ferrari, M. Graciarena, and F. Pitossi, "Chronic expression of low levels of tumor necrosis factor- $\alpha$ in the substantia nigra elicits progressive neurodegeneration, delayed motor symptoms and microglia/macrophage activation," Neurobiology of Disease, vol. 37, no. 3, pp. 630-640, 2010.

[116] M. Chertoff, N. di Paolo, A. Schoeneberg et al., "Neuroprotective and neurodegenerative effects of the chronic expression of tumor necrosis factor $\alpha$ in the nigrostriatal dopaminergic circuit of adult mice," Experimental Neurology, vol. 227, no. 2, pp. 237-251, 2011.

[117] E. Clark, B. Clements, D. Erickson, C. Maccarty, and D. Mulder, "Therapeutic exercises in management of paralysis agitans," Journal of the American Medical Association, vol. 162, no. 11, pp. 1041-1043, 1956.

[118] B. E. Fisher, G. M. Petzinger, K. Nixon et al., "Exerciseinduced behavioral recovery and neuroplasticity in the 1methyl-4-phenyl-1,2,3,6-tetrahydropyridine-lesioned mouse basal ganglia," Journal of Neuroscience Research, vol. 77, no. 3, pp. 378-390, 2004.

[119] G. M. Petzinger, J. P. Walsh, G. Akopian et al., "Effects of treadmill exercise on dopaminergic transmission in the 1methyl-4-phenyl-1,2,3,6-tetrahydropyridine-lesioned mouse model of basal ganglia injury," The Journal of Neuroscience, vol. 27, no. 20, pp. 5291-5300, 2007.

[120] J. L. Tillerson, W. M. Caudle, M. E. Reverón, and G. W. Miller, "Exercise induces behavioral recovery and attenuates neurochemical deficits in rodent models of Parkinson's disease," Neuroscience, vol. 119, no. 3, pp. 899-911, 2003.

[121] B. A. Smith, N. R. Goldberg, and C. K. Meshul, "Effects of treadmill exercise on behavioral recovery and neural changes in the substantia nigra and striatum of the 1-methyl-4-phenyl-1,2,3,6-tetrahydropyridine-lesioned mouse," Brain Research, vol. 1386, pp. 70-80, 2011.

[122] K. Pothakos, M. J. Kurz, and Y. S. Lau, "Restorative effect of endurance exercise on behavioral deficits in the chronic mouse model of Parkinson's disease with severe neurodegeneration," BMC Neuroscience, vol. 10, no. 1, p. 6, 2009.
[123] S. J. O’Dell, N. B. Gross, A. N. Fricks, B. D. Casiano, T. B. Nguyen, and J. F. Marshall, "Running wheel exercise enhances recovery from nigrostriatal dopamine injury without inducing neuroprotection," Neuroscience, vol. 144, no. 3, pp. 1141-1151, 2007.

[124] K. M. Gerecke, Y. Jiao, V. Pagala, and R. J. Smeyne, "Exercise does not protect against MPTP-induced neurotoxicity in BDNF haploinsufficient mice," PLoS One, vol. 7, no. 8, article e43250, 2012.

[125] A. D. Cohen, J. L. Tillerson, A. D. Smith, T. Schallert, and M. J. Zigmond, "Neuroprotective effects of prior limb use in 6-hydroxydopamine-treated rats: possible role of GDNF," Journal of Neurochemistry, vol. 85, no. 2, pp. 299-305, 2003.

[126] C. C. Real, A. F. B. Ferreira, G. P. Chaves-Kirsten, A. S. Torrão, R. S. Pires, and L. R. G. Britto, "BDNF receptor blockade hinders the beneficial effects of exercise in a rat model of Parkinson's disease," Neuroscience, vol. 237, pp. 118-129, 2013.

[127] J. L. Tillerson, A. D. Cohen, J. Philhower, G. W. Miller, M. J. Zigmond, and T. Schallert, "Forced limb-use effects on the behavioral and neurochemical effects of 6-hydroxydopamine," The Journal of Neuroscience, vol. 21, no. 12, pp. 4427-4435, 2001.

[128] M. A. Sacheli, J. L. Neva, B. Lakhani et al., "Exercise increases caudate dopamine release and ventral striatal activation in Parkinson's disease," Movement Disorders, vol. 34, no. 12, pp. 1891-1900, 2019.

[129] M. S. Shin, H. Y. Jeong, D. I. An, H. Y. Lee, and Y. H. Sung, "Treadmill exercise facilitates synaptic plasticity on dopaminergic neurons and fibers in the mouse model with Parkinson's disease," Neuroscience Letters, vol. 621, pp. 28-33, 2016.

[130] H. H. Yin, S. P. Mulcare, M. R. F. Hilário et al., "Dynamic reorganization of striatal circuits during the acquisition and consolidation of a skill," Nature Neuroscience, vol. 12, no. 3, pp. 333-341, 2009.

[131] P. Calabresi, B. Picconi, A. Tozzi, and M. di Filippo, "Dopamine-mediated regulation of corticostriatal synaptic plasticity," Trends in Neurosciences, vol. 30, no. 5, pp. 211-219, 2007.

[132] J. E. VanLeeuwen, G. M. Petzinger, J. P. Walsh, G. K. Akopian, M. Vuckovic, and M. W. Jakowec, "Altered AMPA receptor expression with treadmill exercise in the 1-methyl4-phenyl-1,2,3,6-tetrahydropyridine-lesioned mouse model of basal ganglia injury," Journal of Neuroscience Research, vol. 88, no. 3, pp. 650-668, 2010.

[133] P. K. Chang, D. Verbich, and R. A. McKinney, "AMPA receptors as drug targets in neurological disease-advantages, caveats, and future outlook," The European Journal of Neuroscience, vol. 35, no. 12, pp. 1908-1916, 2012.

[134] P. Calabresi, A. Pisani, D. Centonze, and G. Bernardi, "Synaptic plasticity and physiological interactions between dopamine and glutamate in the striatum," Neuroscience and Biobehavioral Reviews, vol. 21, no. 4, pp. 519-523, 1997.

[135] W. Shen, M. Flajolet, P. Greengard, and D. J. Surmeier, "Dichotomous dopaminergic control of striatal synaptic plasticity," Science, vol. 321, no. 5890, pp. 848-851, 2008.

[136] A. C. Kreitzer and R. C. Malenka, "Endocannabinoid-mediated rescue of striatal LTD and motor deficits in Parkinson's disease models," Nature, vol. 445, no. 7128, pp. 643-647, 2007.

[137] G. Frazzitta, G. Bertotti, D. Uccellini, and R. Maestri, "Parkinson's disease rehabilitation: a pilot study with 1 year follow 
up," Movement Disorders, vol. 25, no. 11, pp. 1762-1763, 2010.

[138] M. Gandolfi, M. Tinazzi, F. Magrinelli et al., "Four-week trunk-specific exercise program decreases forward trunk flexion in Parkinson's disease: a single-blinded, randomized controlled trial," Parkinsonism \& Related Disorders, vol. 64, pp. 268-274, 2019.

[139] D. M. Corcos, J. A. Robichaud, F. J. David et al., “A two-year randomized controlled trial of progressive resistance exercise for Parkinson's disease," Movement Disorders, vol. 28, no. 9, pp. 1230-1240, 2013.

[140] G. Abbruzzese, R. Marchese, L. Avanzino, and E. Pelosin, "Rehabilitation for Parkinson's disease: current outlook and future challenges," Parkinsonism \& Related Disorders, vol. 22, Suppl 1, pp. S60-S64, 2016.

[141] C. F. Ibanez, "Structure-function relationships in the neurotrophin family," Journal of Neurobiology, vol. 25, no. 11, pp. 1349-1361, 1994.

[142] V. Lessmann, K. Gottmann, and M. Malcangio, "Neurotrophin secretion: current facts and future prospects," Progress in Neurobiology, vol. 69, no. 5, pp. 341-374, 2003.

[143] M. V. Chao, "Neurotrophins and their receptors: a convergence point for many signalling pathways," Nature Reviews Neuroscience, vol. 4, no. 4, pp. 299-309, 2003.

[144] B. Lu, P. T. Pang, and N. H. Woo, "The yin and yang of neurotrophin action," Nature Reviews Neuroscience, vol. 6, no. 8, pp. 603-614, 2005.

[145] M. Canossa, O. Griesbeck, B. Berninger, G. Campana, R. Kolbeck, and H. Thoenen, "Neurotrophin release by neurotrophins: implications for activity-dependent neuronal plasticity," Proceedings of the National Academy of Sciences of the United States of America, vol. 94, no. 24, pp. 1327913286, 1997.

[146] S. Patz and P. Wahle, "Neurotrophins induce short-term and long-term changes of cortical neurotrophin expression," The European Journal of Neuroscience, vol. 20, no. 3, pp. 701-708, 2004.

[147] L. F. Lin, D. Doherty, J. Lile, S. Bektesh, and F. Collins, "GDNF: a glial cell line-derived neurotrophic factor for midbrain dopaminergic neurons," Science, vol. 260, no. 5111, pp. 1130-1132, 1993.

[148] M. S. Airaksinen and M. Saarma, "The GDNF family: signalling, biological functions and therapeutic value," Nature Reviews. Neuroscience, vol. 3, no. 5, pp. 383-394, 2002.

[149] O. Lindvall and U. Stenevi, "Dopamine and noradrenaline neurons projecting to the septal area in the rat," Cell and Tissue Research, vol. 190, no. 3, pp. 383-407, 1978.

[150] M. Trupp, N. Belluardo, H. Funakoshi, and C. F. Ibáñez, "Complementary and overlapping expression of glial cell line-derived neurotrophic factor (GDNF), c-ret proto-oncogene, and GDNF receptor-alpha indicates multiple mechanisms of trophic actions in the adult rat CNS," The Journal of Neuroscience, vol. 17, no. 10, pp. 3554-3567, 1997.

[151] A. Pascual, M. Hidalgo-Figueroa, J. I. Piruat, C. O. Pintado, R. Gómez-Díaz, and J. López-Barneo, "Absolute requirement of GDNF for adult catecholaminergic neuron survival," Nature Neuroscience, vol. 11, no. 7, pp. 755-761, 2008.

[152] B. J. Hoffer, A. Hoffman, K. Bowenkamp et al., "Glial cell linederived neurotrophic factor reverses toxin-induced injury to midbrain dopaminergic neurons in vivo," Neuroscience Letters, vol. 182, no. 1, pp. 107-111, 1994.
[153] C. Rosenblad, D. Kirik, B. Devaux, B. Moffat, H. S. Phillips, and A. Björklund, "Protection and regeneration of nigral dopaminergic neurons by neurturin or GDNF in a partial lesion model of Parkinson's disease after administration into the striatum or the lateral ventricle," The European Journal of Neuroscience, vol. 11, no. 5, pp. 1554-1566, 1999.

[154] D. M. Gash, Z. Zhang, A. Ovadia et al., "Functional recovery in parkinsonian monkeys treated with GDNF," Nature, vol. 380, no. 6571, pp. 252-255, 1996.

[155] K. E. Bowenkamp, D. David, P. L. Lapchak et al., "6-Hydroxydopamine induces the loss of the dopaminergic phenotype in substantia nigra neurons of the rat. A possible mechanism for restoration of the nigrostriatal circuit mediated by glial cell line-derived neurotrophic factor," Experimental Brain Research, vol. 111, no. 1, pp. 1-7, 1996.

[156] Z. Chen, Y. F. Chai, L. Cao et al., "Glial cell line-derived neurotrophic factor promotes survival and induces differentiation through the phosphatidylinositol 3-kinase and mitogen-activated protein kinase pathway respectively in PC12 cells," Neuroscience, vol. 104, no. 2, pp. 593-598, 2001.

[157] G. Paratcha, F. Ledda, and C. F. Ibanez, "The neural cell adhesion molecule NCAM is an alternative signaling receptor for GDNF family ligands," Cell, vol. 113, no. 7, pp. 867-879, 2003.

[158] L. Aron and R. Klein, "Repairing the parkinsonian brain with neurotrophic factors," Trends in Neurosciences, vol. 34, no. 2, pp. 88-100, 2011

[159] B. Chen, D. Dowlatshahi, G. M. MacQueen, J. F. Wang, and L. T. Young, "Increased hippocampal BDNF immunoreactivity in subjects treated with antidepressant medication," Biological Psychiatry, vol. 50, no. 4, pp. 260-265, 2001.

[160] S. M. Rocha, A. C. Cristovão, F. L. Campos, C. P. Fonseca, and G. Baltazar, "Astrocyte-derived GDNF is a potent inhibitor of microglial activation," Neurobiology of Disease, vol. 47, no. 3, pp. 407-415, 2012.

[161] D. Kirik, C. Rosenblad, A. Björklund, and R. J. Mandel, "Long-term rAAV-mediated gene transfer of GDNF in the rat Parkinson's model: intrastriatal but not intranigral transduction promotes functional regeneration in the lesioned nigrostriatal system," The Journal of Neuroscience, vol. 20, no. 12 , pp. 4686-4700, 2000.

[162] J. L. Eberling, A. P. Kells, P. Pivirotto et al., "Functional effects of AAV2-GDNF on the dopaminergic nigrostriatal pathway in parkinsonian rhesus monkeys," Human Gene Therapy, vol. 20, no. 5, pp. 511-518, 2009.

[163] M. Brizard, C. Carcenac, A. P. Bemelmans, C. Feuerstein, J. Mallet, and M. Savasta, "Functional reinnervation from remaining DA terminals induced by GDNF lentivirus in a rat model of early Parkinson's disease," Neurobiology of Disease, vol. 21, no. 1, pp. 90-101, 2006.

[164] A. D. Smith, D. A. Kozlowski, M. C. Bohn, and M. J. Zigmond, "Effect of AdGDNF on dopaminergic neurotransmission in the striatum of 6-OHDA-treated rats," Experimental Neurology, vol. 193, no. 2, pp. 420-426, 2005.

[165] J. H. Kordower, S. Palfi, E. Y. Chen et al., "Clinicopathological findings following intraventricular glial-derived neurotrophic factor treatment in a patient with Parkinson's disease," Annals of Neurology, vol. 46, no. 3, pp. 419-424, 1999.

[166] S. S. Gill, N. K. Patel, G. R. Hotton et al., "Direct brain infusion of glial cell line-derived neurotrophic factor in Parkinson disease," Nature Medicine, vol. 9, no. 5, pp. 589-595, 2003. 
[167] A. E. Lang, S. Gill, N. K. Patel et al., "Randomized controlled trial of intraputamenal glial cell line-derived neurotrophic factor infusion in Parkinson disease," Annals of Neurology, vol. 59, no. 3, pp. 459-466, 2006.

[168] M. Salvatore, Y. Ai, B. Fischer et al., "Point source concentration of GDNF may explain failure of phase II clinical trial," Experimental Neurology, vol. 202, no. 2, pp. 497505, 2006.

[169] T. B. Sherer, B. K. Fiske, C. N. Svendsen, A. E. Lang, and J. W. Langston, "Crossroads in GDNF therapy for Parkinson's disease," Movement Disorders, vol. 21, no. 2, pp. 136141, 2006.

[170] L. U. Wahlberg, D. F. Emerich, J. H. Kordower, W. Bell, T. Fradet, and G. Paolone, "Long-term, stable, targeted biodelivery and efficacy of GDNF from encapsulated cells in the rat and Goettingen miniature pig brain," Current Research in Pharmacology and Drug Discovery, vol. 1, pp. 19-29, 2020.

[171] G. Paolone, C. Falcicchia, F. Lovisari et al., "Long-term, targeted delivery of GDNF from encapsulated cells is neuroprotective and reduces seizures in the pilocarpine model of epilepsy," The Journal of Neuroscience, vol. 39, no. 11, pp. 2144-2156, 2019.

[172] C. Falcicchia, G. Paolone, D. F. Emerich et al., "Seizure-suppressant and neuroprotective effects of encapsulated BDNFproducing cells in a rat model of temporal lobe epilepsy," Molecular Therapy - Methods \& Clinical Development, vol. 9, pp. 211-224, 2018.

[173] G. Paolone, A. Brugnoli, L. Arcuri, D. Mercatelli, and M. Morari, "Eltoprazine prevents levodopa-induced dyskinesias by reducing striatal glutamate and direct pathway activity," Movement Disorders, vol. 30, no. 13, pp. 1728-1738, 2015.

[174] A. E. Speck, M. G. Schamne, A. S. Aguiar, R. A. Cunha, and R. D. Prediger, "Treadmill exercise attenuates L-DOPAinduced dyskinesia and increases striatal levels of glial cellderived neurotrophic factor (GDNF) in hemiparkinsonian mice," Molecular Neurobiology, vol. 56, no. 4, pp. 29442951, 2019.

[175] D. K. Binder and H. E. Scharfman, "Brain-derived neurotrophic factor," Growth Factors, vol. 22, no. 3, pp. 123-131, 2009.

[176] K. Schindowski, K. Belarbi, and L. Buee, "Neurotrophic factors in Alzheimer's disease: role of axonal transport," Genes, Brain, and Behavior, vol. 7, Suppl 1, pp. 43-56, 2008.

[177] A. Ciammola, J. Sassone, M. Cannella et al., "Low brainderived neurotrophic factor (BDNF) levels in serum of Huntington's disease patients," American Journal of Medical Genetics. Part B, Neuropsychiatric Genetics, vol. 144B, no. 4, pp. 574-577, 2007.

[178] U. Janakiraman, T. Manivasagam, A. Justin Thenmozhi et al., "Chronic mild stress augments MPTP induced neurotoxicity in a murine model of Parkinson's disease," Physiology \& Behavior, vol. 173, pp. 132-143, 2017.

[179] D. W. Howells, M. J. Porritt, J. Y. F. Wong et al., "Reduced BDNF mRNA expression in the Parkinson's disease substantia nigra," Experimental Neurology, vol. 166, no. 1, pp. 127$135,2000$.

[180] M. Ventriglia, R. Zanardini, C. Bonomini et al., "Serum Brain-Derived Neurotrophic Factor Levels in Different Neurological Diseases," BioMed Research International, vol. 2013, Article ID 901082, 7 pages, 2013.
[181] P. Scalzo, A. Kümmer, T. L. Bretas, F. Cardoso, and A. L. Teixeira, "Serum levels of brain-derived neurotrophic factor correlate with motor impairment in Parkinson's disease," Journal of Neurology, vol. 257, no. 4, pp. 540-545, 2010.

[182] M. Sawada, K. Imamura, and T. Nagatsu, "Role of cytokines in inflammatory process in Parkinson's disease," Journal of Neural Transmission. Supplementum, vol. 70, pp. 373-381, 2006.

[183] K. Knaepen, M. Goekint, E. M. Heyman, and R. Meeusen, "Neuroplasticity - exercise-induced response of peripheral brain-derived neurotrophic factor: a systematic review of experimental studies in human subjects," Sports Medicine, vol. 40, no. 9, pp. 765-801, 2010.

[184] K. L. Szuhany, M. Bugatti, and M. W. Otto, "A meta-analytic review of the effects of exercise on brain-derived neurotrophic factor," Journal of Psychiatric Research, vol. 60, pp. 56-64, 2015.

[185] V. Castellano and L. J. White, "Serum brain-derived neurotrophic factor response to aerobic exercise in multiple sclerosis," Journal of the Neurological Sciences, vol. 269, no. 1-2, pp. 85-91, 2008.

[186] M. J. Green, S. L. Matheson, A. Shepherd, C. S. Weickert, and V. J. Carr, "Brain-derived neurotrophic factor levels in schizophrenia: a systematic review with meta-analysis," Molecular Psychiatry, vol. 16, no. 9, pp. 960-972, 2011.

[187] J. E. Ahlskog, Y. E. Geda, N. R. Graff-Radford, and R. C. Petersen, "Physical exercise as a preventive or diseasemodifying treatment of dementia and brain aging," Mayo Clinic Proceedings, vol. 86, no. 9, pp. 876-884, 2011.

[188] S. A. Neeper, F. Góauctemez-Pinilla, J. Choi, and C. Cotman, "Exercise and brain neurotrophins," Nature, vol. 373, no. 6510, p. 109, 1995.

[189] C. Zuccato and E. Cattaneo, "Brain-derived neurotrophic factor in neurodegenerative diseases," Nature Reviews Neurology, vol. 5, no. 6, pp. 311-322, 2009.

[190] C. Campos, N. B. F. Rocha, E. Lattari, F. Paes, A. E. Nardi, and S. Machado, "Exercise-induced neuroprotective effects on neurodegenerative diseases: the key role of trophic factors," Expert Review of Neurotherapeutics, vol. 16, no. 6, pp. 723-734, 2016.

[191] P. G. da Silva, D. D. Domingues, L. A. de Carvalho, S. Allodi, and C. L. Correa, "Neurotrophic factors in Parkinson's disease are regulated by exercise: evidence-based practice," Journal of the Neurological Sciences, vol. 363, pp. 5-15, 2016.

[192] A. Figurov, L. D. Pozzo-Miller, P. Olafsson, T. Wang, and B. Lu, "Regulation of synaptic responses to high-frequency stimulation and LTP by neurotrophins in the hippocampus," Nature, vol. 381, no. 6584, pp. 706-709, 1996.

[193] N. H. Woo, H. K. Teng, C. J. Siao et al., "Activation of p75NTR by proBDNF facilitates hippocampal long-term depression," Nature Neuroscience, vol. 8, no. 8, pp. 10691077, 2005.

[194] K. M. Gerecke, Y. Jiao, A. Pani, V. Pagala, and R. J. Smeyne, "Exercise protects against MPTP-induced neurotoxicity in mice," Brain Research, vol. 1341, pp. 72-83, 2010.

[195] P. Cadet, W. Zhu, K. Mantione et al., "Cyclic exercise induces anti-inflammatory signal molecule increases in the plasma of Parkinson's patients," International Journal of Molecular Medicine, vol. 12, no. 4, pp. 485-492, 2003. 
[196] S. Moon, M. Schmidt, I. Smirnova, Y. Colgrove, and W. Liu, "Qigong exercise may reduce serum TNF- $\alpha$ levels and improve sleep in people with Parkinson's disease: a pilot study," Medicines, vol. 4, no. 2, p. 23, 2017.

[197] D. Pochmann, P. K. Peccin, I. R. V. da Silva et al., "Cytokine modulation in response to acute and chronic aquatic therapy intervention in Parkinson disease individuals: a pilot study," Neuroscience Letters, vol. 674, pp. 30-35, 2018. 